\title{
INTERNAL REFLECTING HORIZONS IN SPITSBERGEN GLACIERS
}

\author{
by
}

\section{J. L. Bamber}

(Scott Polar Research Institute, University of Cambridge, Cambridge CB2 1ER, U.K.)

\begin{abstract}
A single pronounced internal reflecting horizon has been observed on radio echo-sounding from over 30 glaciers in Spitsbergen. They are often present along the entire length of the glacier, remaining at a fairly constant depth $(100-200 \mathrm{~m})$ below the ice surface. Echo-strength data from radio echo-sounding have been used to obtain reflection coefficients, for these horizons, of between -15 and $-25 \mathrm{~dB}$. Combined with results of ice-core studies, the possible causes of this internal layer are investigated. The presence of water is found to be the most likely explanation, indicating the existence, at depth, of a layer of temperate ice.
\end{abstract}

\section{INTRODUCTION}

A striking feature observed on radio echo-sounding (RES) records from many of the thicker $(>200 \mathrm{~m})$ glaciers in Spitsbergen is the existence of a single continuous internal reflecting horizon (IRH) ranging in depth from 100 to $200 \mathrm{~m}$ below the surface and persisting for up to $20 \mathrm{~km}$ (Fig.1). It is found in all parts of the glacier but has not been observed to reach the surface at the snout.

In 1983, the Scott Polar Research Institute (SPRI) undertook an extensive airborne RES programme in Svalbard (Drewry and Liestøl 1985). $60 \mathrm{MHz}$ data were recorded digitally, affording precise measurement of echo strength and hence allowing the calculation of reflection coefficients (RCs). Thirty-four glaciers and six ice caps in Spitsbergen were sounded and a comprehensive network of flight lines flown over Nordaustlandet. Several Soviet RES programmes have also been undertaken using equipment operating at higher frequencies $(620$ or $440 \mathrm{MHz})$ (Macheret and others 1984). Previously in 1980, 33 glaciers had been sounded throughout Spitsbergen using analogue-recording techniques, the equipment being mounted in a helicopter (Dowdeswell and others 1984[a]).

Svalbard glaciers can be difficult to sound due to high dielectric absorption (much of the ice is close to the pressure melting-point), internal scattering, and thicknesses of up to $560 \mathrm{~m}$, and has on occasion led to misinterpretation of reflections (Dowdeswell and others 1984[b]).

The glaciers of Svalbard are classed as sub-polar; they are not temperate throughout but may have zones close to or at the pressure melting-point. $10 \mathrm{~m}$ temperatures measured in the ablation zone on Austfonna $\left(-8.6^{\circ} \mathrm{C}\right)$ are significantly lower than those recorded about $300 \mathrm{~m}$ higher in elevation (above the firn line), which range from $-1{ }^{\circ} \mathrm{C}$ (personal communication from A. Semb) to $-6.4^{\circ} \mathrm{C}$ (Dowdeswell unpublished). This variability is due to the large amount of latent heat absorbed from melt water at depth in the firn in the accumulation zone. The thermal regime of these glaciers is thus complex and many have parts close to the pressure melting-point with water present at the bed. The size of the ice masses in Svalbard is also very varied, ranging from small valley glaciers less than $10 \mathrm{~km}$ long and $100 \mathrm{~m}$ thick to the ice caps on Nordaustlandet covering an area of $10600 \mathrm{~km}^{2}$.

\section{DATA RECORDING IN 1983}

The RES data were recorded as the geometric mean of eight individual wave forms, each comprising 256 samples taken at $100 \mathrm{~ns}$ intervals.
The ice-surface elevation changes were tracked automatically but for the weaker, noisier, and more intermittent bedrock and internal signals this was not possible. A differentiated continuous display of the digital data (known as a "Z"-scope display) was manually digitized. The errors of depth measurement incurred are negligible in comparison to the digital sampling length (equivalent to $8.4 \mathrm{~m}$ in ice, which defines the maximum resolution of an individual pulse).

Absolute elevations were calculated using terrain clearance from the radar sounder and a pressure altitude calibrated by overflying areas of open water. Interpolation between pulses enabled the relative surface elevation to be found to within $2 \mathrm{~m}$ (Drewry and Liestøl 1985). Ice
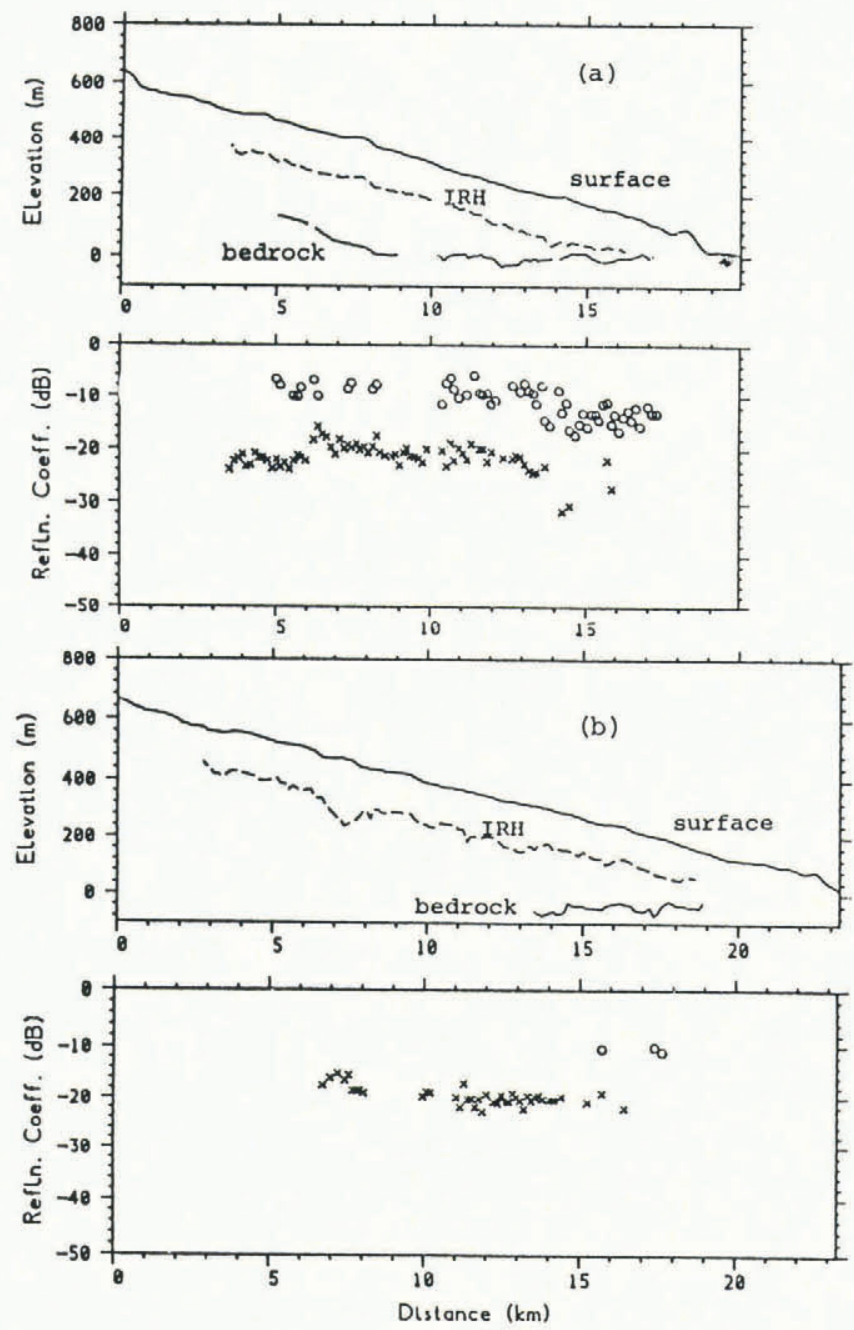

Fig.1. Typical glacier profiles with IRHs (dashed). Shown below are the respective RCs for the bedrock (circles) and IRH (crosses). (a) Uversbreen; (b) Kongsvegan; note loss of bedrock echo towards the accumulation zone. 
thicknesses were calculated using a mean value for the permittivity of ice of 3.17 (equivalent to a velocity of $168 \mathrm{~m} / \mu \mathrm{s}$ )

Navigation was carried out using a combination of a Tactical Airborne Navigation System (TANS) and visual landmarks recorded to $\pm 1 \mathrm{~s}$ (equivalent to $60 \mathrm{~m}$ along track). Depending on the nature of the landmark, an error of, at maximum, $6 \mathrm{~s}(360 \mathrm{~m})$ could also be introduced. Across-track errors are more variable but are nowhere more than $800 \mathrm{~m}$ and typically $<400 \mathrm{~m}$. Wherever possible, flight tracks followed the centre lines of the glaciers.

\section{GLACIER PROFILES - GENERAL OBSERVATIONS}

Two typical glacier profiles with very distinct IRHs are shown in Fig.1. They bear a stronger relationship to the surface than the bedrock, lying at a fairly uniform depth. They do not, however, represent a "smooth" surface and
Soviet data collected at $440 \mathrm{MHz}$ indicate that they may not be continuous on a scale of centimetres.

This is in strong constrast to the sedimentary layers observed in Antarctic ice (e.g. Millar unpublished) which appear to follow the bottom topography more closely. In profile (b) the bedrock is only present in the ablation zone (due to a combination of signal obscuration by scatter echoes and higher total attenuation), another common feature. Bedrock RCs (plotted as circles) are usually between 5 and $15 \mathrm{~dB}$ stronger than the IRH values. The RC data relating to the IRHs are discussed in detail in the next section. On a qualitative basis, the radar records show markedly increased internal scattering below the IRH, which on several glaciers has led to the obscuration of the bottom echo and which is a common feature of RES data from temperate ice masses.

Of the 34 glaciers sounded in 1983 , six had no resolvable returns (and showed signs of heavy scattering),

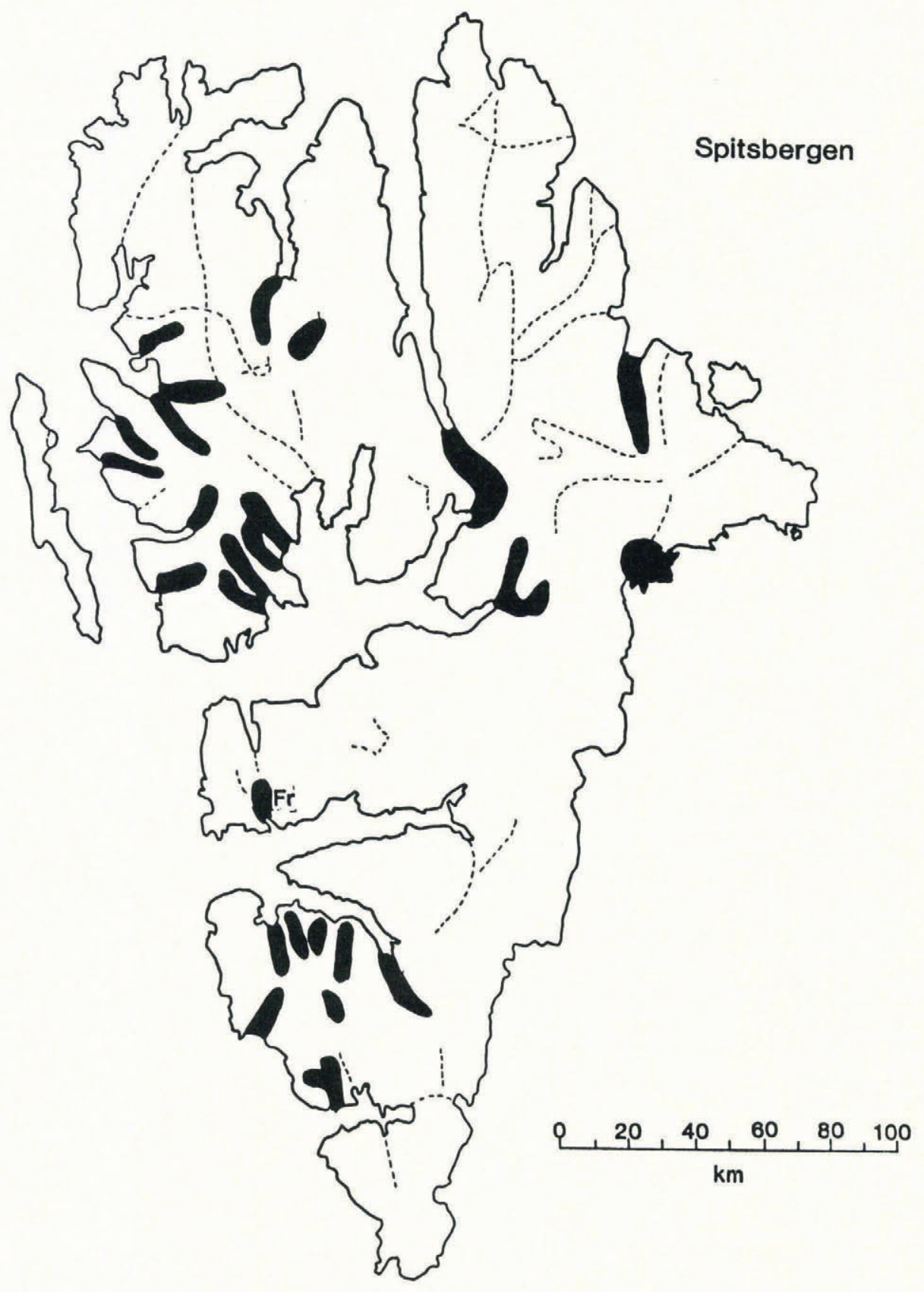

Fig.2. Geographical distribution of all IRHS observed (solid), including Soviet and SPRI 1980 data

( $\mathrm{Fr}$, Fridtjovbreen). The dashed lines show track sounded but absence of an IRH. 
and from the remaining 28 only three had no IRH present. In 1980, 38 glaciers were sounded, 20 of which had resolvable echoes and of these ten had distinct IRHs. Although this latter data set has a greater proportion of glaciers with no IRH, they are generally thinner $(<200 \mathrm{~m})$, conforming to the 1983 results. The geographical distribution of IRHs is shown in Fig. 2 and only indicates a limited pattern. One of the coldest ice masses of the archipelago, Austfonna, possesses no IRH and fewer IRHs are observed on the north-eastern part of Spitsbergen, a region of relatively high-altitude mountain terrain covered by a thin ice layer (typically between 100 and $200 \mathrm{~m}$ thick). The dashed lines represent areas sounded but with an absence of IRHs. They indicate that the regional distribution of glaciers with IRHs is not due solely to the areal coverage of flight lines, though the greater occurrence of IRHs on the western side of the island may be caused by this.

\section{REFLECTION COEFFICIENTS AND ICE-CORE ANALYSIS}

The major consideration in obtaining experimental values of RCs from RES data is the estimation of the dielectric absorption, B. This is a function of the complex dielectric permittivity $\epsilon^{*}$, where $\epsilon^{*}=\epsilon^{\prime}-i \epsilon^{\prime \prime}$ and $\epsilon^{\prime}$ is the relative permittivity and $\epsilon^{\prime \prime}$ is the dielectric loss factor. $\epsilon^{*}$ is in turn dependent primarily upon the ice temperature though the presence of impurities and/or water may also have a significant influence (Glen and Paren 1975). (Note that, for convenience, the asterisk will be dropped in future references to the complex permittivity.)

For the majority of Spitsbergen glaciers the temperature regime is poorly known. There is considerable uncertainty in extrapolating results from one glacier to another (Zagorodnov and Zotikov 1981). Consequently, mean absorption in the ice was calculated, where possible, from the variation of attenuation with depth of the bedrock echo (Fig.3). This assumes that both the RC and ice properties are invariant over the region covered. The justification for this approximation can be assessed by the spread in points about the fitted regression line. Data from glaciers with a correlation coefficient of $<0.8$ were rejected. Values for $B$ were typically between 4.0 and $4.5 \mathrm{~dB} / 100 \mathrm{~m}$. Attenuation of ten showed a poor correlation to ice thickness and for these glaciers a linear temperature profile, with surface temperature $\mathrm{T}_{\mathrm{S}}=-4^{\circ} \mathrm{C}$ and the bed at the pressure melting-point, was used. Data on the variation with temperature of the absorption were taken from Jiracek (1965). The greatest errors in this approach are not due to the uncertainty in temperature profile (changing $T_{S}$ from $-4^{\circ}$ to $-1{ }^{\circ} \mathrm{C}$, for a $250 \mathrm{~m}$ column of ice, alters the total absorption by only $3.5 \mathrm{~dB}$ ) but in the value of $\mathrm{B}$ assumed

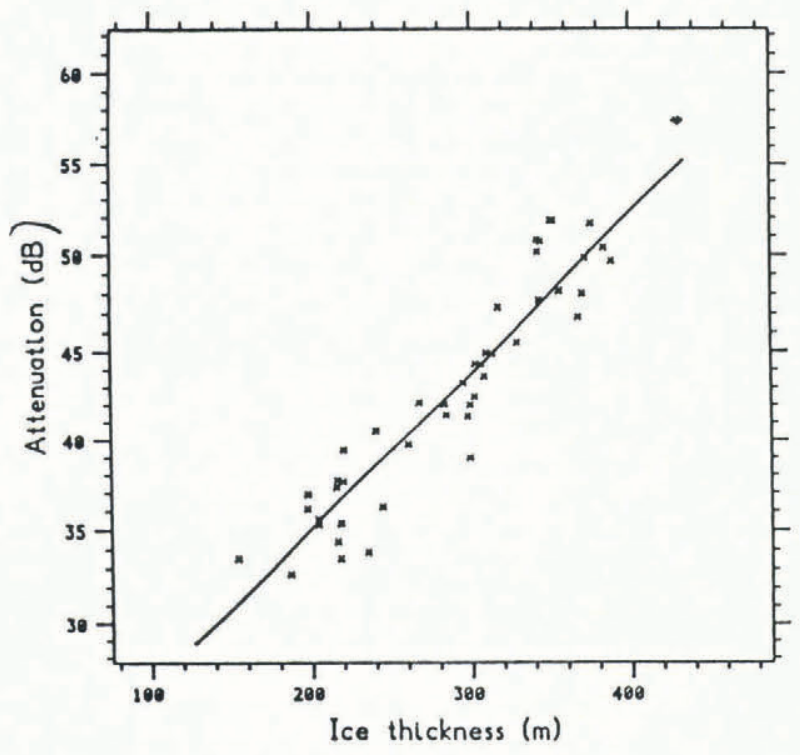

Fig.3. Graph of total absorption by the ice vs depth. Data from the bedrock echoes from a glacier with an IRH (Borebreen). $\mathrm{B}=4.2 \mathrm{~dB} / 100 \mathrm{~m}$ in this example. for a given temperature. Errors in the total dielectric absorption (and hence RCs) are estimated as no more than $\pm 2 \mathrm{~dB} / 100 \mathrm{~m}$ ice thickness.

RCs were calculated using the radar equation which is, in $\log$ form

$P_{r}=P_{t}+20 \log \frac{\lambda G}{8 \pi(H+z / n)}+R C-\frac{2 B Z}{100}$

where $\lambda$ is free-space wavelength, $G$ is forward antenna gain, $\mathrm{H}$ is terrain clearance, $\mathrm{Z}$ is ice thickness, $\mathrm{n}$ is refractive index of ice $\left(\equiv \sqrt{\epsilon^{\top}}\right), \quad B$ is the mean dielectric absorption/100 m, $P_{r}$ and $P_{t}$ are receiver and transmitter power in dB. IRH values of RCs lie in the range -15 to $-30 \mathrm{~dB}$ with an average value of approximately $-20 \mathrm{~dB}$; errors depend on depth but are generally $<5 \mathrm{~dB}$.

\section{INTERPRETATION}

Reflection of $\mathrm{E}-\mathrm{M}$ radiation from any surface implies a change in dielectric properties at the point of reflection.

$\mathrm{RC}=\left|\frac{\eta_{1}-\eta_{2}}{n_{1}+\eta_{2}}\right|^{2}$

$\eta=\left[\frac{\mu_{0}}{\epsilon_{0} \epsilon^{\prime}+\frac{\sigma^{\prime}}{i \omega}}\right]^{1 / 2} \ldots$

$\mu_{0}$ is permeability, $\sigma^{\prime}$ is real conductivity, $\epsilon_{0}$ is permittivity of free space, and $\omega$ is the angular frequency of radio waves. In ice, a change in $\sigma^{\prime}$ or $\epsilon^{\prime}$ can be caused by a variation in density, impurities, temperature, crystal size and orientation, or from a layer of another material such as moraine. The uniformity in depth to the IRH virtually precludes the possibility that it might be of a depositional origin. If the most likely cause of the IRHs is due to a change in water content, it is necessary to describe the dielectric properties of water-laden ice. Such a two-phase system, with components of differing $\sigma^{\prime}$ and $\epsilon^{\prime}$, causes interfacial polarization known as Maxwell-Wagner polarization and the strength of this is dependent upon the shape and size of the dispersoid (water). In the next section it is suggested that the distribution of water is likely to be highly anisotropic, being found in channels and conduits rather than on an intragranular scale. Consequently, a generalized mixture formula (known as the Looyenga equation), which has been successfully applied to firn of widely varying density (Glen and Paren 1975), was used:

$\epsilon_{\mathrm{m}}^{1 / 3}=\epsilon_{\mathrm{i}}{ }^{1 / 3}+\mathrm{V}_{\mathrm{w}}\left[\epsilon_{\mathrm{w}}{ }^{1 / 3}-\epsilon_{\mathrm{i}}{ }^{1 / 3}\right]$

where $V_{w}$ is fractional water content and $\epsilon_{w}^{\prime}=86, \epsilon_{i}^{\prime}=$ 3.17 (Smith unpublished) and $\epsilon_{\text {air }}=1.0$.

Values for the RC of a boundary between air-filled and water-filled ice have been calculated for water volumes between 1 and $6 \%$ (Fig.4). The effect of water conductivity is negligible. It can be seen that a water content of approximately $5 \%$ is necessary to explain the observed RCs. This does not represent the mean water content below the IRH, but only that which is observed close to the "wet"/"dry" boundary. It should be noted that there is a two-fold increase predicted, in the water content, for an increase of the RC from -25 to $-20 \mathrm{~dB}$. Given the systematic errors inherent in calculating experimental values of the RC, it is not possible to define a precise water volume at the boundary, and even less so below it. What can be established is that the average water content, at the level of the IRH, is $>3 \%$ and that this is considerably more than the values typically found in temperate glaciers (Raymond and Harrison 1975; Vallon and others 1976), which range from $0.1 \%$ to $1 \%$ at maximum. In the next section it is suggested that the primary influence on the level of the IRH is the subglacial water pressure and, if the ice above it is less permeable than below, then it is 


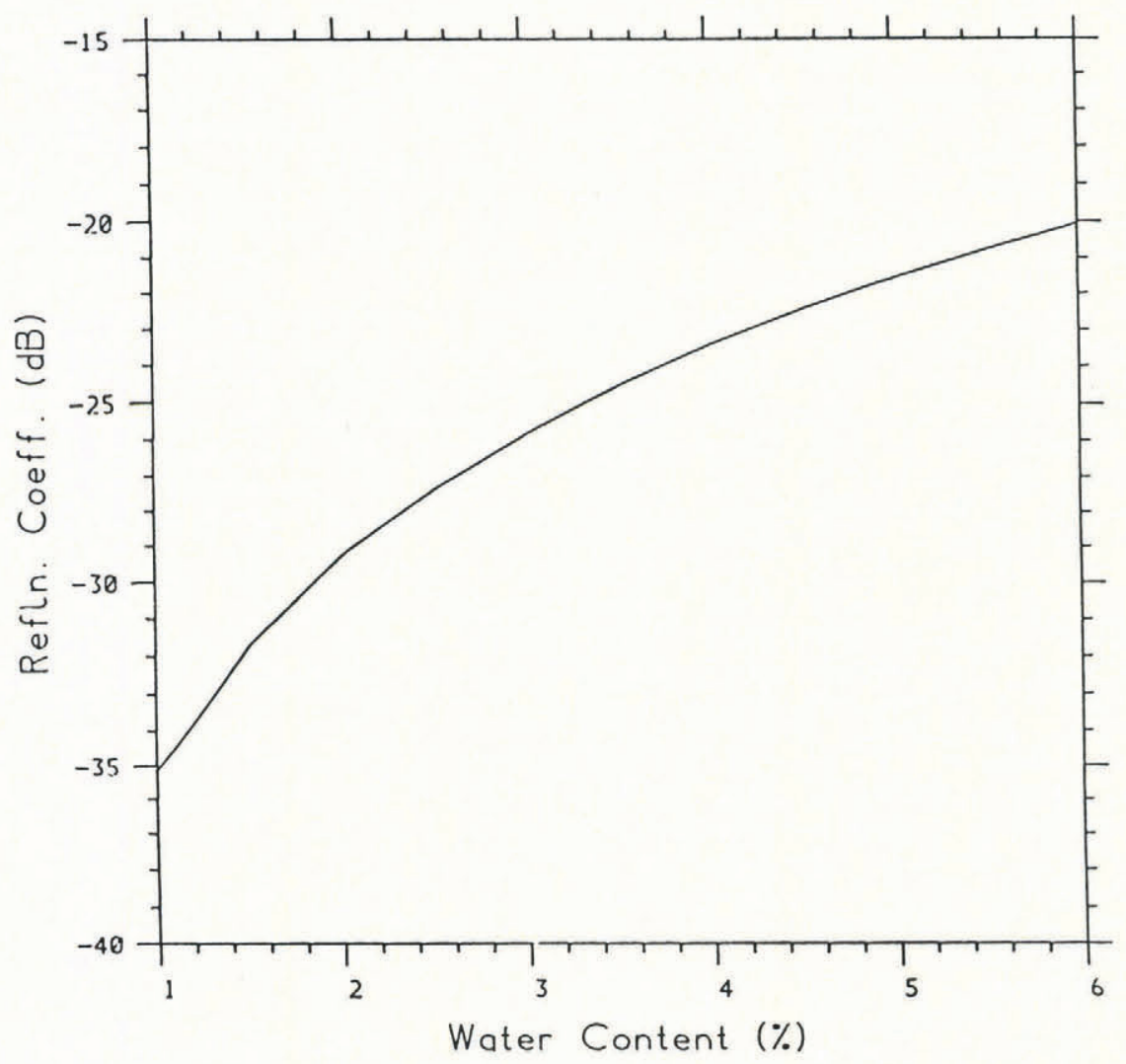

Fig.4. Theoretical reflection coefficients for a boundary between "dry" ice and ice with a given water content, calculated using the Looyenga mixture formula.

conceivable that the englacial water content will be a maximum near the interface.

A radio echo-logging experiment (Macheret and others 1984) on Fridtjovbreen (Fig.2) revealed a dielectric discontinuity at a depth coincident with an observed IRH. Above the IRH $\epsilon=3.035$ and below $\epsilon=4.125$. The authors calculated that such a change could be produced by a water content (f) of $3.8 \%$. This is similar to the values predicted by the RCs but their measurements only went to a depth of about $30 \mathrm{~m}$ below the dielectric boundary and it is consequently difficult to deduce what the bulk water content might be. It is also difficult to envisage a mechanism by which such a high water content may be maintained throughout the lower layer.

Other causes for the IRHs have been considered but do not satisfactorily explain the observations from the IRHs. Paren and Robin (1975) included discussion of RC strengths arising from a density fluctuation in polar ice sheets and obtained a maximum $\mathrm{RC}$ of $-51 \mathrm{~dB}$ for a discontinuity at a depth of $100 \mathrm{~m}$. Even taking the largest variation possible between ice of density $830 \mathrm{~kg} / \mathrm{m}^{-3}$ and $910 \mathrm{~kg} / \mathrm{m}^{-3}$ gives an RC too low to explain the observed values. It also seems unlikely that such a layer would persist along the entire length of the glacier from accumulation to ablation zone. Dirt bands or other depositional discontinuities have even lower RCs (Millar unpublished). It is not only the RCs but the striking uniformity in depth and extent of the IRHs from Spitsbergen that reduces the possibility that they are sedimentary in origin.

A water layer of approximately $15 \mathrm{~cm}$ thickness or more could give similar values of $\mathrm{RC}$ but such a layer could not extend unbroken for $15 \mathrm{~km}$ or more and would still not explain the radio echo-logging results from Fridtjovbreen (Macheret and others 1984).

\section{SIGNIFICANCE OF A WATER-SATURATED LAYER}

A reasonable hypothesis for the IRHs is water saturation of the glacier below the IRH and it has several important implications. Interpretation of RES data possessing an IRH immediately indicates the general thermal regime of the glacier. The presence of water and hence the possibility of sliding at the bed is suggested and is hence useful in interpreting the dynamic properties. Duval (1977), for instance, has shown that there is an order of magnitude increase in the strain-rate for ice with $\mathrm{V}_{\mathrm{w}}=0.01$ relative to that with a negligible concentration. Here lies a system with possible positive feed-back. Water production is directly proportional to the strain-rate, $\overline{\mathrm{e}}$

$\mathrm{q}=\frac{2 \dot{\mathrm{e}} \tau}{\mathrm{L}}$,

$\mathrm{L}$ is latent heat of fusion of ice, $\tau$ is shear stress, and $\mathrm{q}$ is water production due to strain heating.

This does not lead to an instability related to temperature as considered by Clarke and others (1977), where rapid warming and the attainment of pressure melting at. the bed are the relevant factors, but is nonetheless a phenomenon regulated by heat production. The difficulty in developing this model is in understanding how drainage and permeability are related to the water content; at volume fractions as high as 1\%, Nye and Frank's (1973) model of intragranular flow has been shown to be inapplicable (Lliboutry 1976).

The presence of water will affect the crystal fabric, reducing strain hardening and crystal size (Lliboutry 1976). If impurities are concentrated at grain boundaries, as has been suggested by Wolff and Paren (1984), then flushing may have an important influence on the purity and hence dielectric properties of the ice.

FACTORS AFFECTING THE LEVEL OF THE IRH

Classical ground-water flow principles (namely, Darcy's law and Dupuit's assumptions which are that, for small slopes, the hydraulic head is equal to the surface gradient and that stream lines are parallel to the surface) can be used to find the piezometric surface of an unconfined aquifer based on basic well-known boundary conditions 


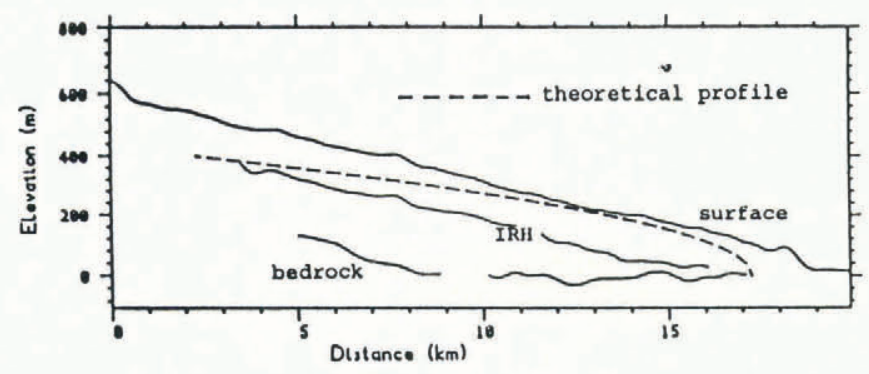

Fig.5. Comparison of the theoretical piezometric surface, as calculated from basic ground-water flow principles, with the IRH in Uversbreen.

(Fetter 1980). Such a system might represent ice possessing water at the grain boundaries as suggested by Nye and Frank (1973). This model gives rise to a parabolic relationship between hydraulic head and distance down-glacier, which is depressed by including a term for drainage at the bed. In Fig.5 the real profile is compared with one calculated from the aforementioned assumptions. It can be seen that poor agreement is obtained, the theoretical profile having a convex-upward profile.

\section{RÖTHLISBERGER CHANNELS}

Another model, considered by Röthlisberger (1972), is that the water flows in a small number of englacial or subglacial channels. The piezometric surface is now defined by the water pressure within these channels. The equation used was flow-law index (assumed to be 3 in this case). It was integrated numerically to obtain a profile of the piezometric surface along the centre line of the glacier. This equation describes the water pressure, $\mathrm{p}$, within a gradient conduit (i.e. one which follows the hydraulic grade line) and was used because it allows a continuous surface to be calculated, even for negative bedrock slopes, using the real surface and bedrock profiles. These were converted into an algebraic form using cubic spline curves, so that the integral could be evaluated at all points. The flow rate, Q, was estimated by calculating the water produced by strain heating in the bottom layer and bottom melting due to the geothermal heat flux. It was assumed to vary linearly, reaching a maximum at the snout.

Results of the modelling procedure, for two glaciers ((a) Tunabreen, (b) Borebreen) possessing IRHs are shown in Fig.6. For curve (1) $\mathrm{A}=4 \times 10^{7} \mathrm{~Pa} \mathrm{~s} \mathrm{~s}^{1 / 3}, \mathrm{~K}=100 \mathrm{~m}^{1 / 3}$ $\mathrm{s}^{-1}$; (2) $\mathrm{A}=6 \times 10^{7} \mathrm{~Pa} \mathrm{~s} \mathrm{~s}^{1 / 3}, \mathrm{~K}=100 \mathrm{~m}^{1 / 3} \mathrm{~s}^{-1}$, (3) $\mathrm{A}=6$ $\times 10^{7} \mathrm{~Pa} \mathrm{~s}^{1 / 3}, \mathrm{~K}=200 \mathrm{~m}^{1 / 3} \mathrm{~s}^{-1}$

It can be seen that the general form of the IRHs is well described by this model. It is not suggested that the values of $A$ or $K$ represent those to be found within the glaciers or that flow will be in a single channel at the hydraulic grade line, but the analysis does indicate that the level of the IRH, along the glacier centre line, has a similar form to that described by a Röthlisberger channel. Physically, such a model implies that the ice has a large-scale permeability below the IRH, via conduits and channels anisotropically distributed within the glacier. These water bodies represent discrete radar scatterers (hence the heavy internal scattering observed below the IRH) as opposed to a uniform distribution of small-scale veins and lenses existing at grain boundaries (Nye and Frank 1973). The former model is supported by RES data collected by the Soviets (personal communication from Y.Y. Macheret) at

$$
\frac{d p}{d x}=\frac{D^{8 / 11} K^{-6 / 11}(n A)^{-8 n / 11} Q^{-2 / 11}\left(P-\frac{\rho_{i}}{\rho_{W}} p\right)^{8 n / 11}}{\left[1-\left[\frac{1}{\rho_{W} g} D^{8 / 11} K^{-6 / 11}(n A)^{-8 n / 11} Q^{-2 / 11}\left(P-\frac{\rho_{i}}{\rho_{W}} p\right)^{8 n / 11}\right]^{2}\right] 1 / 2}-\rho_{W} g \tan \beta \ldots
$$

where $\mathbf{P}=\rho_{\mathrm{i}} \mathrm{gH}$ (where $\mathbf{H}$ is ice thickness and $\rho_{\mathrm{i}}$ is ice density), $\tan \beta$ is bedrock gradient, $D=3.63 \times 10^{10}$ $\left(\mathrm{N} \mathrm{m}^{-2}\right)^{11 / 8} \mathrm{~m}^{-3 / 8}$ (a physical constant), $\mathrm{K}$ is roughness coefficient of the channel, A is flow-law constant, and $n$ is
$440 \mathrm{MHz}$, where on some glaciers the IRH appears to be composed of an array of individual scattering centres which is continuous on a kilometre scale but broken on the metre scale.

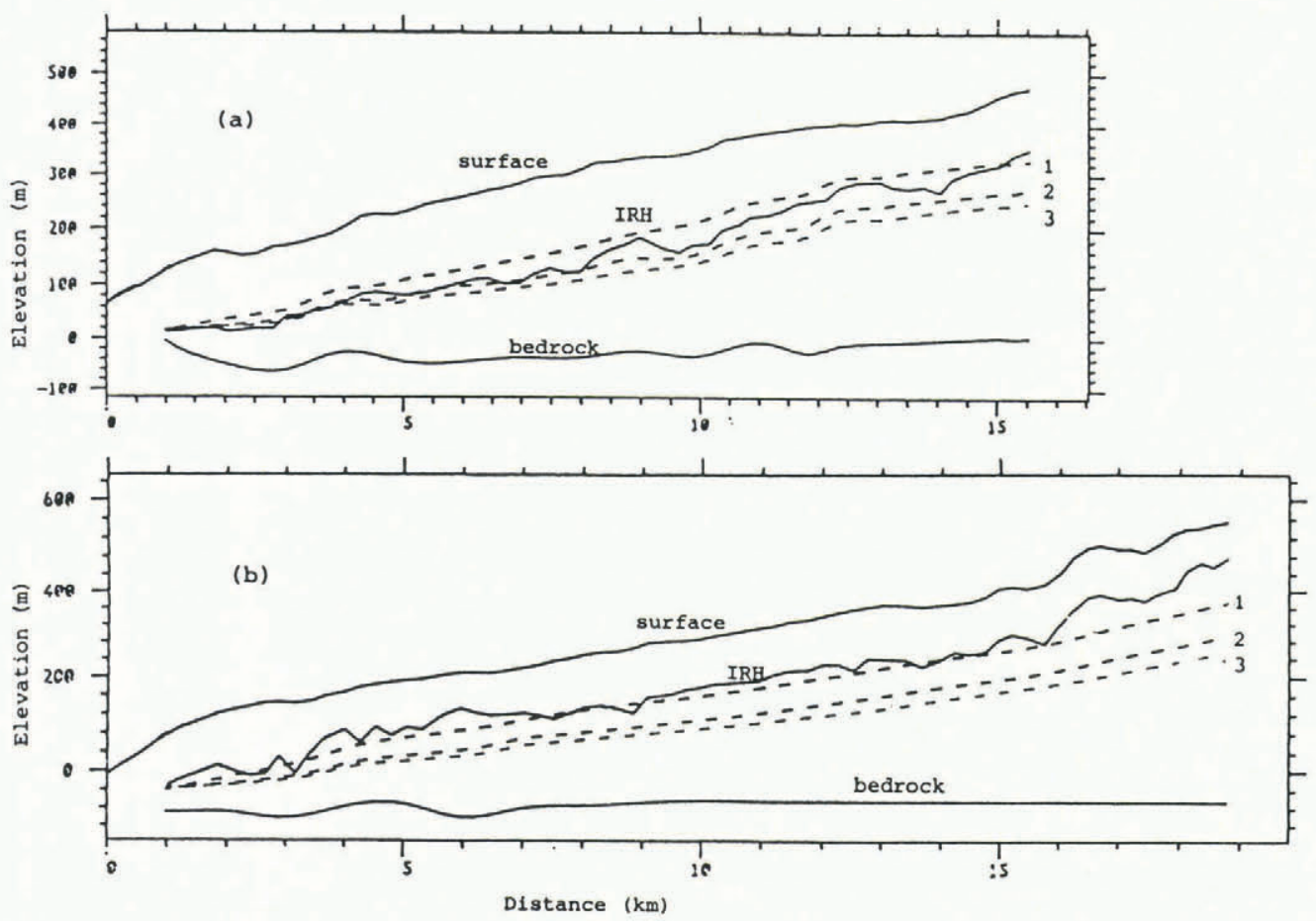

Fig.6. Comparison between the hydraulic grade line (dashed curves) for a Röthlisberger channel and the observed IRHs (solid line) on (a) Tunabreen and (b) Borebreen. For curve (1) $\mathrm{A}=4 \times 10^{7}$ $\mathrm{Pa} \mathrm{s} \mathrm{s}^{1 / 3}, \quad \mathrm{~K}=100 \mathrm{~m}^{1 / 3} \mathrm{~s}^{-1} ; \quad(2) \quad \mathrm{A}=6 \times 10^{7} \mathrm{~Pa} \mathrm{~s}^{1 / 3}, \quad \mathrm{~K}=100 \mathrm{~m}^{1 / 3} \mathrm{~s}^{-1}$; $\mathrm{A}=6 \times 10^{7} \mathrm{~Pa} \mathrm{~s}^{1 / 3} \mathrm{~K}=200 \mathrm{~m}^{1 / 3} \mathrm{~s}^{-1}$. 


\section{THERMAL REGULATION}

One more factor that may have an important influence on the level of the IRH is heat conduction across the surface. Unlike tenperate glaciers, $10 \mathrm{~m}$ temperatures in Spitsbergen ice can be several degrees below $0^{\circ} \mathrm{C}$ (Dowdeswell unpublished) and it is possible that the IRH may reflect the pressure-melting isotherm. A simple calculation of the temperature gradient needed, to have a significant influence on the water level, suggests that this effect is of secondary importance.

The heat involved in freezing $3 \%$ of water is $9 \times 10^{6}$ $\mathrm{J} \mathrm{m}^{-3}$. Assuming a temperature gradient of $0.1{ }^{\circ} \mathrm{C} \mathrm{m}^{-1}$ at the interface, the heat flux across the boundary is $0.21 \mathrm{~W}$ $\mathrm{m}^{-2}$. With these values, it would take about $496 \mathrm{~d}$ to freeze a layer $1 \mathrm{~m}$ thick. The water pressure, and hence water level, in temperate glaciers varies on a much larger scale than this on a seasonal basis. If the same is true for Spitsbergen glaciers, it seems unlikely that thermal regulation will be as important as water pressure. The small-scale roughness of the IRH supports this conclusion, as a thermally regulated boundary would be expected to be smooth on a $10 \mathrm{~m}$ scale. Although heat conduction across the boundary may not be important in defining its level, the fact that the overlying ice is cold, and possibly impermeable as a consequence, probably is important.

\section{CONCLUSIONS}

The most likely cause for the observed IRHs is the presence of a water-saturated zone. This hypothesis is supported by data from RES and bore-hole measurements. The concept of a two-layer glacier is thus invoked, an upper non-temperate layer and a lower temperate zone with potentially different properties which affect the dielectric and dynamic nature of the ice. Numerical modelling studies indicate that the most likely factor influencing the level of the IRH is the subglacial water pressure.

\section{ACKNOWLEDGEMENTS}

The author would like to thank Drs D J Drewry and J A Dowdeswell for their helpful advice and comments. Funding was through a UK NERC grant GR3/4463 and a NERC studentship to the author.

\section{REFERENCES}

Clarke G K C, Nitsan U, Paterson W S B 1977 Strain heating and creep instability in glaciers and ice sheets. Reviews of Geophysics and Space Physics 15(2): 235-247

Dowdeswell J A Unpublished Remote sensing studies of Svalbard glaciers. (PhD thesis, University of Cambridge, 1984)

Dowdeswell J A, Drewry D J, Liestøl O, Orheim O 1984[a] Airborne radio echo sounding of sub-polar glaciers in Spitsbergen. Norsk Polarinstitutt. Skrifter 182

Dowdeswell J A, Drewry D J, Liestøl O, Orheim O 1984[b] Radio-echo sounding of Spitsbergen glaciers: problems in the interpretation of layer and bottom returns. Journal of Glaciology 30(104): 16-21

Drewry D J, Liestøl O 1985 Glaciological investigations of surging ice caps in Nordaustlandet, Svalbard, 1983. Polar Record 22(139): 359-378

Duval P 1977 The role of the water content on the creep rate of polycrystalline ice. International Association of Hydrological Sciences Publication 118 (General Assembly of Grenoble 1975 - Isotopes and Impurities in Snow and Ice): $263-271$

Fetter C W Jr 1980 Applied hydrogeology. Columbus, OH, Charles E. Merrill

Glen J W, Paren J G 1975 The electrical properties of snow and ice. Journal of Glaciology 15(73): 15-38

Jiracek G R Unpublished Radio echo sounding of Antarctic ice. (MSc thesis, University of Wisconsin, 1965)

Lliboutry L 1976 Physical processes in temperate glaciers. Journal of Glaciology 16(74): 151-158
Macheret Yu Ya, Vasilenko Ye V, Gromyko A N, Zhuravlev A B 1984 Radiolokatsionnyy karotazh skvazhiny na lednike Frit'of, Shpitsbergen [Radio echo logging of the bore hole on the Fridtjov glacier, Spitsbergen]. Materialy Glyatsiologicheskikh Issledovaniy. Khronika. Obsuzhdeniya 50: 198-203

Millar D H M Unpublished Radio echo layering in polar ice sheets. (PhD thesis, University of Cambridge, 1981)

Nye J F, Frank F C 1973 Hydrology of the intragranular veins in a temperate glacier. International Association of Scientific Hydrology Publication 95 (Symposium on the Hydrology of Glaciers, Cambridge 7-13 September 1969): 157-161

Paren J G, Robin G de Q 1975 Internal reflections in polar ice sheets. Journal of Glaciology 14(71): 251-259

Raymond C F, Harrison W D 1975 Some observations on the behavior of the liquid and gas phases in temperate glacier ice. Journal of Glaciology 14(71): 213-233

Röthlisberger H 1972 Water pressure in intra- and subglacial channels. Journal of Glaciology 11(62): 177-203

Smith B M E Unpublished Radio echo sounding studies of glaciers. ( $\mathrm{PhD}$ thesis, University of Cambridge, 1971)

Vallon M, Petit J-R, Fabre B 1976 Study of an ice core to the bedrock in the accumulation zone of an Alpine glacier. Journal of Glaciology 17(75): 13-28

Wolff E W, Paren J G 1984 A two-phase model of electrical conduction in polar ice sheets. Journal of Geophysical Research 89(B11): 9433-9438

Zagorodnov V S, Zotikov I A 1981 Kernovoye bureniye na Shpitsbergene [Ice core drilling on Spitsbergen]. Materialy Glyatsiologicheskikh Issledovaniy. Khronika. Obsuzhdeniya 40: $157-163$ 